\title{
Introduction to the Government Services and Information Minitrack
}

\author{
Jay P. Kesan \\ University of Illinois at Urbana-Champaign \\ kesan@illinois.edu
}

\author{
Luis Felipe Luna-Reyes \\ University at Albany in Albany, NY \\ 1luna-reyes@albany.edu
}

\author{
Ludwig Christian Schaupp \\ West Virginia University \\ christian.schaupp@mail.wvu.edu
}

\begin{abstract}
Improvements in technology have a significant impact on the way government agencies interact with their constituents. This mini-track seeks research papers and practitioner reports addressing citizens' expectations and acceptance of e-government services across government levels and branches, success factors for e-government services development and implementation, value assessments of e-government services, and methodologies, techniques, and tools for service composition. We are particularly interested in the characteristics, development, implementation, uses, and evaluation of e-government services and systems.
\end{abstract}

E-government services pose numerous challenges in terms of interoperability of services, design of services, optimization of process chains, identification and assessment of the value-chain of services, governmental accounting, cross-organizational service chains, workflow support of e-services, integration of internal IT support, G2G and G2C e-services, outsourcing of services, digital preservation, electronic records management, etc... On the other hand, egovernment services also provide opportunities for service innovation and citizen participation through processes of co-production. Research to guide the development, management and evaluation of egovernment services is in great demand in this important and rapidly growing domain. 